\title{
Measurements of image shifts using an edge-extracted joint transform correlator
}

\author{
${ }^{1,2}$ Fan Chao \\ ${ }^{1}$ College of Information Science and Engineering of Henan University of \\ Technology, Zheng Zhou, 450001 \\ ${ }^{2}$ Key Laboratory of the Grain Information Processing and Control of the Ministry of \\ Education of China, Zheng Zhou
}

Received: 27.12 .2017

\begin{abstract}
To measure accurately sub-pixel image shifts for the space cameras with high resolutions, an improved joint-transform correlation (JTC) algorithm is put forward, which combines fuzzy-edge detection and high-boost filtering. First we explain the principles of measurements of the image shifts based on the JTC. Considering that most of the important information is kept in and described by the edges of image, a modified fuzzy-edge detection algorithm by Pal and King is then used to extract the edge information of the input image. The joint power spectrum is subjected to high-boost filtering to enhance detail-containing image components and eliminate low-frequency noises. Finally, an experimental platform is built and the performance of image-shift measurements based on the improved JTC is studied. The results testify that the measurement errors are normally distributed, with a zero mean and mean-square deviation less than $\sim 0.1$ pixel, whenever the shift between two correlated images changes from 0 to 25 pixel. As a result, our JTC technique facilitates highly accurate measurements of sub-pixel image shifts.
\end{abstract}

Keywords: joint-transform correlators, image shifts, fuzzy edge extraction, highboost filtering

PACS: $42.79 . \mathrm{Hp}$

UDC: 004.932

\section{Introduction}

Satellite remote sensing is regarded as an example of novel high technologies, which develop at high speed nowadays. A lot of scientific data and dynamic information can be available with the high-resolution remote sensing. Since a remote-sensing camera is loaded on a satellite that moves at high speed, a relative motion is produced between the camera and the imaged objects, when the camera is working. This induces a blur of the image which is called as image shift. The image shifts are caused by many factors, such as scrolling of satellite, adjustment of solar arrays, vibration, variation of orbit, errors of drifting angle, etc. [1, 2]. With increasing resolution of the remote sensing cameras, the image shifts become a factor of major influence, which lowers resolution and affects seriously the quality of images [3, 4$]$.

Although the image shifts produced by some factors have already been analyzed by researchers, a complex operating environment of the space cameras causes the image shifts to be random and irregular, so that would be hard to study the image shifts using solely theoretical arguments. Hence, different methods have been put forward to measure and compensate the image shifts. They can be classified into two categories, digital-image processing methods and optical ones [5-8]. No matter which of the methods is used, accurate measurements of the image shifts are 
the most important. In all of these measurements, a joint-transform correlator (JTC) is considered as one of the most efficient methods because it combines the advantages of both optical and electronic processing. In frame of this method, sequential images are captured by a camera and correlated by the JTC, so that the image shifts can be measured in online and real-time regimes. Note that since the image shifts are produced randomly [9], they can be continuous and do not equal to integral multiples of a pixel, i.e. there can be a lot of small sub-pixel image shifts [10, 11]. Measuring these sub-pixel shifts accurately represents a key problem of the JTCs.

Considering that the edges of imaged objects contain the most important information for measuring the image shifts when using the JTC, the processing method put forward in the present study combines fuzzy-edge recognition for the input image and high-boost filtering for the resulting joint power spectrum. In Section 2 we describe the principles of measuring the sub-pixel image shifts. Section 3 explains a modified Pal and King algorithm for the fuzzy-edge detection, which is used to extract the edges of imaged objects. A high-boost filter based on the Laplace kernel, which is adopted to highlight the outlines of the joint power spectrum (JPS) and improve the measurement accuracy for the image shifts, is a subject of Section 4. Finally, we verify experimentally the performance of our method in Section 5 and draw the main conclusion in Section 6.

\section{Principles of measurements of image shifts based on the JTC}

A structural scheme of our optoelectronic JTC is displayed in Fig. 1. Here a He-Ne laser is used as a light source. Being modulated by an attenuator, focused by a microscopic objective and filtered by a pinhole, a laser beam is expanded with an air-spaced doublet collimating lens. A camera CCD1 takes a role of a space camera. It is used to catch sequential images of an object at high speed. Then two adjacent images are input on a spatial light modulator (SLM) together with a joint image. Here the first image serves as a reference one and the second image is used as a target one. Note that there exists a sub-pixel image shift between these two images. After that, the joint image is Fourier transformed by a lens and a JPS is recorded using a camera CCD2. After the JPS is reloaded again at the SLM through PC2, the JPS is transformed by a Fourier lens, and the correlation is obtained with a camera $\mathrm{CCD} 2$.

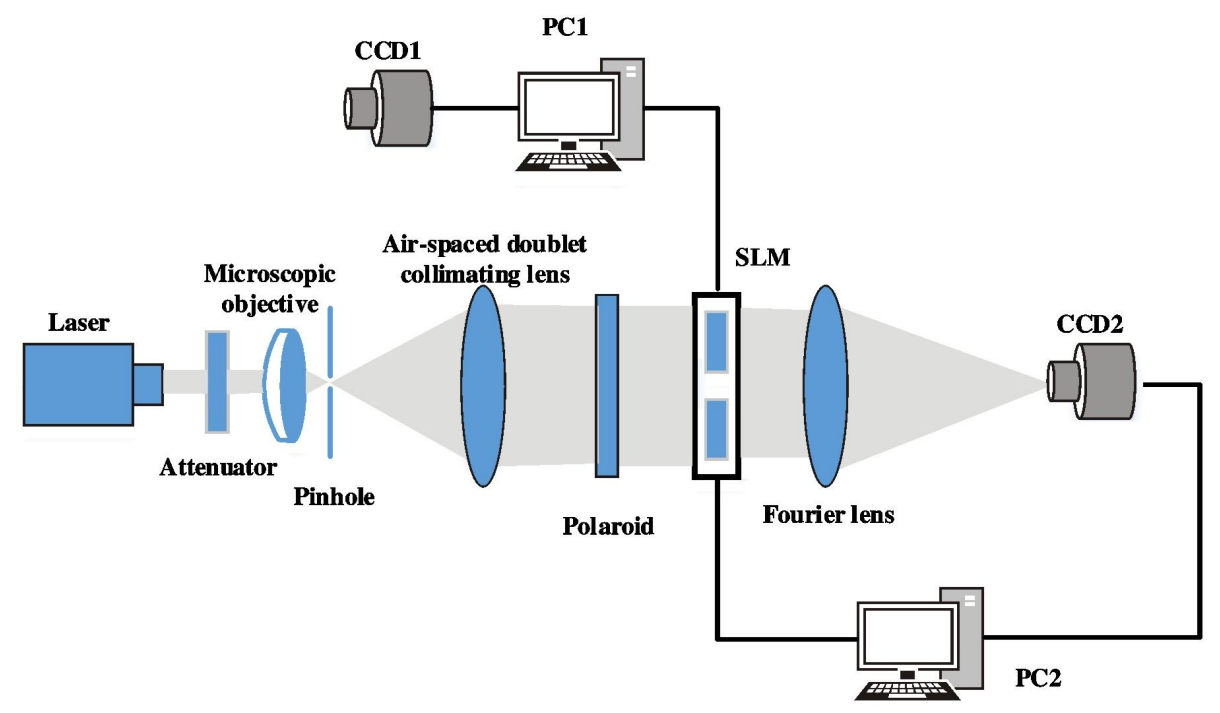

Fig. 1. Structural scheme of our optoelectronic JTC. 
We denote the two adjacent images as reference $(r(x, y))$ and target $(t(x, y))$ images. The both are input on the SLM symmetrically, so that the appropriate centres are located at $(0, a)$ and $(0,-a)$. If compared with the image $r(x, y)$, the scene in the image $t(x, y)$ is moved some distances $\Delta x$ and $\Delta y$ along the $x$ and $y$ directions, respectively. Thus, the input of the JTC is given by

$$
E(x, y)=r(x, y-a)+t(x+\Delta x, y+a+\Delta y) .
$$

Then $E(x, y)$ is Fourier transformed by the lens, and the JPS $P(u, v)$ recorded with CCD2. It is given by

$$
\begin{aligned}
P(u, v) & =|G(u, v)|^{2}=|R(u, v)|^{2}+|T(u, v)|^{2} \\
& +R(u, v) T^{*}(u, v) \exp \{-2 i \pi[u \Delta x+(2 a+\Delta y) v]\} \\
& +R^{*}(u, v) T(u, v) \exp \{2 i \pi[u \Delta x+(2 a+\Delta y) v]\},
\end{aligned}
$$

where $R(u, v)$ and $T(u, v)$ are the Fourier transforms of respectively $r(x, y)$ and $t(x, y), u$ and $v$ include dimensional scaling factors determined by the focal length of lens, the light wavelength, and the pixel pitches on the camera focal plane and SLM, and the superscript * implies complex conjugate. After the JPS is transformed again, the corresponding correlation can be obtained:

$$
\begin{aligned}
c(x, y)= & t(x, y) \oplus t(x, y)+r(x, y) \oplus r(x, y)+t(x, y) \oplus r(x, y) \otimes \\
& \delta(x-\Delta x, y-2 a-\Delta y)+r(x, y) \oplus t(x, y) \otimes \delta(x+\Delta x, y+2 a+\Delta y)
\end{aligned}
$$

where the symbol $\otimes$ denotes the convolution, $\otimes$ the correlation and $\delta$ the delta function. The first two terms in the r. h. s. of Eq. (3) correspond to auto-correlation, and the last two to cross-correlation. As seen from Eq. (3), when the reference and target images contain the same information, with slight shifts $\Delta x$ and $\Delta y$ only, then these shifts can be measured by finding displacement between the positions of actual cross-correlation peaks and their 'ideal' positions $(0, \pm 2 a)$.

\section{Edge extraction for the input image based on modified fuzzy algorithm by Pal and King}

Usually, the contrast and the signal-to-noise ratio of the image caught with remote sensing cameras are poor. This means that the peak of the cross-correlation cannot be detected accurately and the power of the side lobes is strong enough. To improve detection precision, many methods have been put forward. For example, the images can be processed in the input plane of the SLM, e.g. the techniques of mathematical morphology, edge detection and median filtering $[8,12,13]$. The other methods are based on power-spectrum processing, including fringe modulation, binarization of power and subtraction of spectrum [14-16].

The edge is an important characteristic of the object. It represents a basic structure of image and supplies more important clues for visual recognition with the JTC. Hence, to improve the measurement accuracy for the image shifts, the edge of the input image must be extracted. Although the common algorithms of edge extracting are simple and fast, the edges can only be reliably detected for distinct enough images. In case of the space cameras with high resolution, the objects on the ground are complex. This implies that different gray levels are included in the image. Moreover, both the background noise and the pattern noise are also available in the image, according to the working principles of the space cameras. It is therefore difficult to extract continuous edges and control the noises using the common methods, such as those based upon Canny or Sobel operators. Considering the characteristics of remote sensing images, in the present work we use a fuzzy-edge detection technique based on the algorithm suggested by Pal and King.

The principle behind the Pal and King algorithm [17] is such that the image is first mapped 
onto a fuzzy membership matrix using a membership function. Then the matrix is enhanced to highlight the edge information. Finally, the processed membership matrix is inversely transformed into enhanced image and the edge is extracted [18]. There are some drawbacks involved in the Pal and King algorithm: (1) some gray information is lost after fuzzy-image enhancement because the range of the membership function is not strictly from 0 to 1 ; (2) the membership function depends on the reciprocal fuzzy factor $F_{d}$ and the exponential fuzzy factor $F_{e}$; however, these parameters are adjustable and there is no reasonable criterion to decide their optimal values for different images; (3) there is a lot of floating point arithmetic in the mapping of the membership matrix and the inverse transformation, which consumes much time and deteriorates a real-time property of the algorithm; and (4) the edge is enhanced via iterating many time moments, but when the times elapses, the details of the edge disappear.

To overcome the shortages mentioned above, a modified Pal and King algorithm for the fuzzyedge detection has been suggested in Ref. [19]. Its procedures can be described as follows:

Step 1. Selecting a threshold $T$ of the image. There are many methods for determining the threshold for a gray image, which are given by the algorithms suggested by Otsu, Kittle and Kapur, as well as an adaptive-threshold method. Considering that the images taken by the space cameras are changeable and complex, here we use the Kapur algorithm to decide the optimal threshold parameter $T$.

Step 2. Defining a new membership function. The gray image is transformed into a binary one, using the threshold $T$; the regions where the gray values are larger than $T$ are regarded as a background and they are considered as a target otherwise. However, the pixels with their gray values just equal to $T$ can be classified as either the background or the target, i.e. these pixels are the fuzziest. Then the value of the fuzziness function amounts to 0.5 , and the corresponding fuzziness degree is the largest. So, a new membership function is defined as

$$
p_{m n}=H\left(l_{m n}\right)=\left\{\begin{array}{ll}
\frac{1}{2}\left(\frac{l_{m n}-l_{\min }}{\tau-l_{\min }}\right)^{2} & l_{\min } \leq l_{m n} \leq T \\
1-\frac{1}{2}\left(\frac{l_{m n}-l_{\max }}{\tau-l_{\max }}\right)^{2} & T<l_{m n} \leq l_{\max }
\end{array} .\right.
$$

Here $p_{m n}$ is the value of the fuzzy membership function, which is also given by $H\left(l_{m n}\right)$ (with $l_{m n}$ being the gray value of the image at the row $m$ and the column $\left.n\right), l_{\min }$ and $l_{\max }$ correspond respectively to the minimal and maximal gray values of the image, and $T$ is the threshold obtained in the step 1. According to Eq. (4), one can see that $p_{m n} \in[0 ; 0.5]$ when $l_{\min } \leq l_{m n} \leq T$, and $p_{m n} \in(0.5 ; 1]$ when $T \leq l_{m n} \leq l_{\max }$. Combining these two outcomes, one can see that the membership value for the whole image ranges from 0 to 1 . This overcomes the shortage of the traditional Pal and King algorithm, and ensures that all of the gray information can be fuzzily enhanced.

Step 3. Smoothing. The processed image must be smoothed before being enhanced, in order to weaken the influence of noises on the edge extracting. A $3 \times 3$ low-pass filtering kernel $B$ is used to convolute with the image:

$$
B=\frac{1}{16}\left[\begin{array}{lll}
1 & 2 & 1 \\
2 & 4 & 2 \\
1 & 2 & 1
\end{array}\right]
$$


Step 4. Enhancement. The fuzzy image is enhanced by a nonlinear transformation for $p_{m n}$, so that the transformation can be described as

$$
p_{m n}^{\prime}=T_{r}\left(p_{m n}\right)=T_{1}\left(T_{r-1}\left(p_{m n}\right)\right), \quad r=1,2, \ldots,
$$

where

$$
T_{1}\left(p_{m n}\right)=\left\{\begin{array}{ll}
\frac{p_{m n}^{2}}{p_{r}}, & 0 \leq p_{m n} \leq p_{c} \\
1-\frac{\left(1-p_{m n}\right)^{2}}{1-p_{r}}, & p_{c}<p_{m n} \leq 1
\end{array},\right.
$$

In Eqs. (6) and (7), $p_{m n}^{\prime}$ is the enhanced value of the fuzzy membership function, $T_{r}\left(p_{m n}\right)$ corresponds to the nonlinear transformation repeated $r$ times with $p_{m n}$, and $p_{c}$ is a constant. According to definition of the fuzzy membership degree given by Eq. (4), the transformed membership value $p_{m n}^{\prime}$ must be increased (when $p_{m n}>0.5$ ) or decreased (when $p_{m n} \leq 0.5$ ) after enhancement. Then the $p_{c}$ value is set to be 0.5 .

Step 5. Inverse transformation of $p_{m n}^{\prime}$. The $p_{m n}^{\prime}$ quantity is inversely transformed to obtain the fuzzy image X'. The expression for the inverse transformation can be obtained with Eq. (4), i.e. we have

$$
l_{m n}^{\prime}=H^{-1}\left(l_{m n}\right)= \begin{cases}\sqrt{2 p_{m n}^{\prime}}\left(T-l_{\text {min }}\right)+l_{\text {min }}, & l_{\text {min }} \leq l_{m n} \leq T \\ \sqrt{2\left(1-p_{m n}^{\prime}\right)}\left(T-l_{\text {max }}\right), & T \leq l_{m n} \leq l_{\text {max }}\end{cases}
$$

where $l_{m n}^{\prime}$ is the gray value of the transformed fuzzy image $\mathrm{X}^{\prime}$, and $H^{-1}\left(l_{m n}\right)$ represents the operation inverse with respect to $H\left(l_{m n}\right)$ (see Eq. (4)).

Step 6. Edge extraction. The edge of the fuzzy image $X$ ' can be extracted using 'min' or 'max' operators.

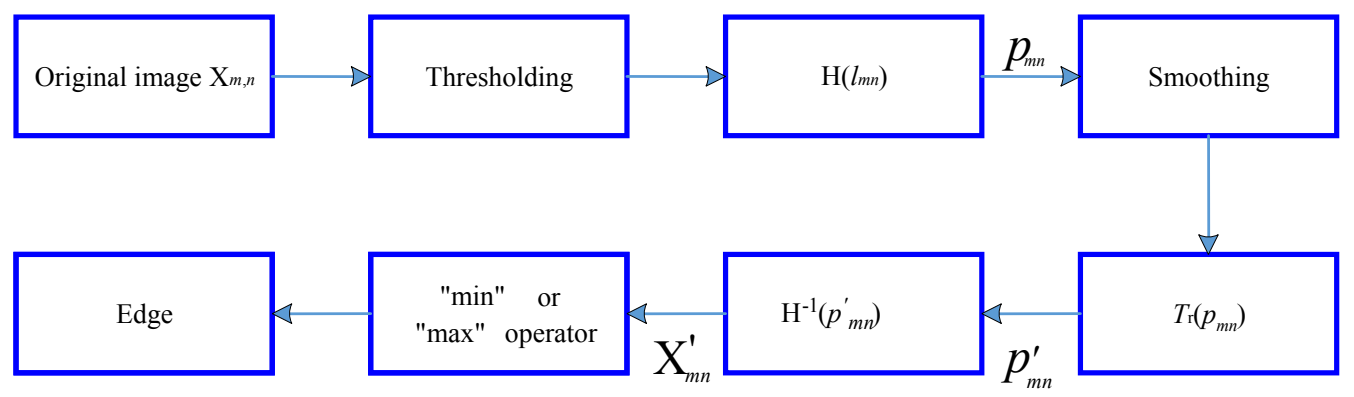

Fig. 2. Flow chart of our modified Pal and King algorithm.

In accordance with the above steps, in Fig. 2 we illustrate a flow chart of our modified Pal and King algorithm for the case of fuzzy-edge extraction.

\section{Enhancement of JPS based on high-boost filtering}

The essence of the high-boost filtering for the JPS has to perform a quadratic differential processing in the power-spectrum plane, using a differential operator. This can enhance the highfrequency components and weaken the parts of which gray levels vary slowly. Then the filtered power spectrum is added to the original one. Then the main details of the spectrum are kept and even enhanced and, at the same time, the noise is eliminated. As a result, the power of cross- 
correlation becomes stronger and more concentrated, and the measurement accuracy for the image shifts improves largely.

Basing on Eq. (2), one can express the differential operation of the JPS as follows:

$$
\nabla^{2} P=\frac{\partial^{2} p}{\partial u^{2}}+\frac{\partial^{2} p}{\partial v^{2}}
$$

The first derivative of $P(u, v)$ can be approximately described by a first-order difference:

$$
\begin{aligned}
& \frac{\partial p(u, v)}{\partial u}=\Delta_{u} P(u, v)=P(u, v)-P(u-1, v), \\
& \frac{\partial p(u, v)}{\partial v}=\Delta_{v} P(u, v)=P(u, v)-P(u, v-1) .
\end{aligned}
$$

The second-order partial derivative can be written as

$$
\begin{aligned}
& \frac{\partial p^{2}(u, v)}{\partial u^{2}}=\Delta_{u} P(u, v)-\Delta_{u} P(u-1, v)=P(u, v)-2 P(u-1, v)+P(u-2, v), \\
& \frac{\partial p^{2}(u, v)}{\partial v^{2}}=\Delta_{v} P(u, v)-\Delta_{v} P(u, v-1)=P(u, v)-2 P(u, v-1)+P(u, v-2) .
\end{aligned}
$$

Then the Laplace transform of the JPS is given by

$$
\nabla^{2} P=\frac{\partial p^{2}}{\partial u^{2}}+\frac{\partial p^{2}}{\partial v^{2}}=2 P(u, v)-2 P(u-1, v)-2 P(u, v-1)+P(u-2, v)+P(u, v-2) \text {. }
$$

The gray value for some pixels becomes negative after filtering, thus implying that the gray information is missed when compared with the original power spectrum. To keep a sharpening effect, the filtered power spectrum is added to the original one, which can be written as

$$
P_{h b}(u, v)=P(u, v)+\nabla^{2} P(u, v) .
$$

Here $P_{h b}(u, v)$ denotes the power spectrum boosted with the high-boost filtering.

\section{Experiments}

We have built an experimental setup of our JTC, as displayed in Fig. 1. An electrically addressed TFT-LCD XGA3 (made by the Forth Dimension Displays Co. Ltd, England) is used as a SLM. Its spatial resolution is equal to $1024 \times 768$ pixel $^{2}$, the pixel pitch to $18 \times 18 \mu \mathrm{m}^{2}$, and the pixel dimensions to $13 \mu \mathrm{m}(\mathrm{H}) \times 10 \mu \mathrm{m}(\mathrm{V})$. We use a CCD device EL-400ME (made by DTA Co. Ltd, Italy), with the resolution $768 \times 512$ pixel $^{2}$ and the pixel dimensions $9 \times 9 \mu \mathrm{m}^{2}$. To make the CCD array aperture just match the size of the zero order of the Fourier diffraction pattern of our pixelated SLM, one should select the focal length of the Fourier lens as follows:

$$
f=N_{2} d_{2} d_{1} / \lambda,
$$

where $N_{2}$ is the number of pixels in each row of the CCD camera, $d_{2}$ the size of pixels of the CCD camera, $d_{1}$ the size of pixels of the SLM, and $\lambda$ the wavelength of illuminating light. When a HeNe laser is used as a coherent source, the focal length is equal to $f=196.6 \mathrm{~mm}$. The $f$ parameter of the lens is chosen so that the highest spatial frequency at the SLM can match the physical size of the CCD camera. Following from this condition, a doublet lens with the diameter of $30 \mathrm{~mm}$ is selected as the Fourier lens.

To verify the measurement accuracy of our JTC that combines the fuzzy-edge extraction and high-boost filtering principles, a number of images taken by a satellite camera Quickbird2 have been used in our experiments. First, a sub-picture with the size of 256 $\times 256$ pixel $^{2}$ is extracted from the whole image. To model a sub-pixel image motion, the extracted sub-image is shifted along the 
$x$ and $y$ directions using a linear interpolation. The appropriate motions are changed from 0 to 50 pixels. Finally, both the original sub-image and the shifted image are binned together along the two directions by two adjacent pixels. They are used as reference and target images for the JTC. The sizes of the both images are then equal to $128 \times 128$ pixel $^{2}$. In this manner the input images with the resolutions reduced by a factor of two along the both directions can be obtained, while the image shifts between these images are in the region 0-25 pixels. Considering the Nyquist sampling for the original image, this produces an accurate modelling of sub-pixel translation.

The down-sampled input images are fuzzy-edge extracted and Fourier transformed, and the JPS is obtained. Then the JPS suffers the high-boost filtering and becomes Fourier transformed again. Finally, the relevant correlation is calculated. As a result, the positions of the crosscorrelation peaks are searched for, from which the image shifts are measured. A flow chart of these measurement procedures is given in Fig. 3.

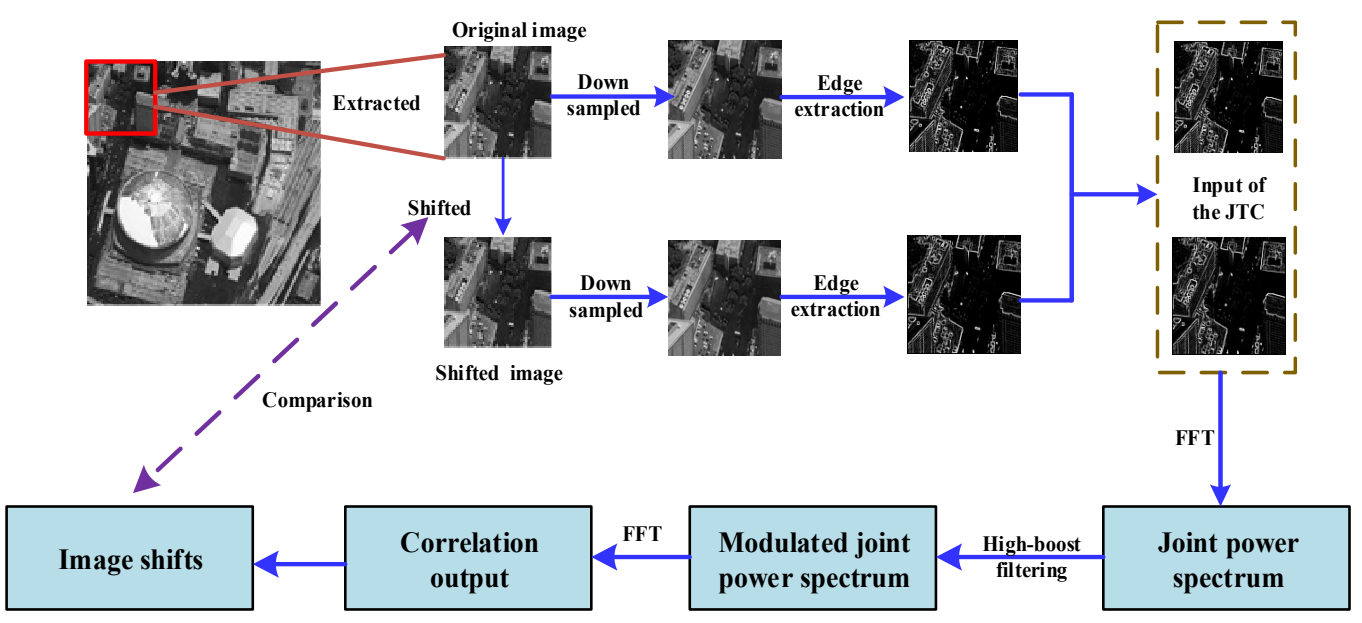

Fig. 3. Flow chart of measuring the image shifts.

Now we wish to study influence of the edge-extraction algorithm on the performance of measurements of the image shifts. The edges of different sub-images are extracted using the improved Pal and King algorithm and some other edge-extraction methods, which are usually used in the image processing. These include the operators suggested by Sobel, Robert, Prewitt, Log and Canny, as well as the Gaussian and Canny operator. As an example, Fig. 4 shows the results of extraction for two sub-images. One can draw the following conclusions:

(1) All of the edges extracted using different conventional operators are discrete and incomplete;

(2) In the case of Sobel, Roberts and Prewitt operators, the edges are detected just by calculating the differences along different directions, with no filtering. Therefore a lot of the edge information is lost for the images with low contrasts, when the above operators are used;

(3) When the images are filtered, enhanced and edge-extracted using the operators suggested by Log, Canny and Gauss-Canny, most of the edge points can be extracted even if the contrast is low. However, a lot of irrelevant information is also extracted, which becomes a noise for the JTC. Then the measurement accuracy gets lower, too. If compared with the above operators, the modified Pal and King algorithm yields in extracting continuous, distinct and complete edges. The main information in the image is kept, and the characteristics of the sub-image are clearly reflected. This implies improved measurement accuracy for the image shifts. 


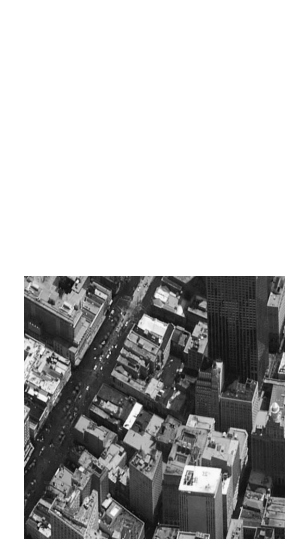

(a)

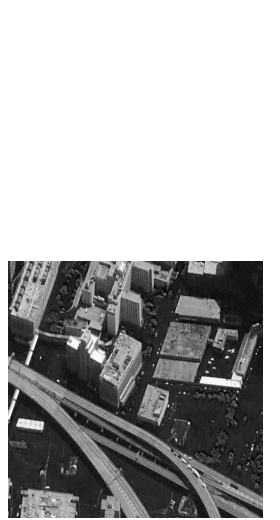

(d)

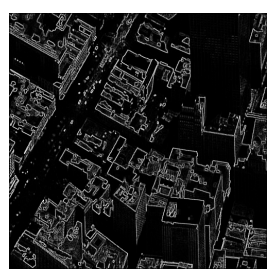

(b)

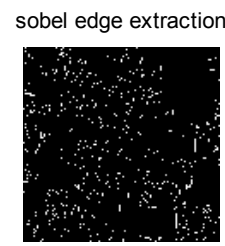

log edge extraction

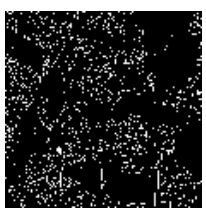

sobel edge extraction

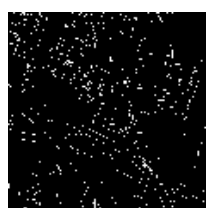

log edge extraction

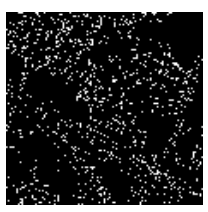

(e)

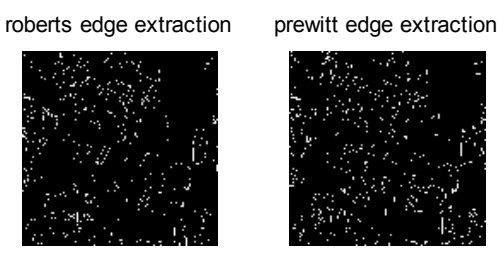

canny edge extraction gasuss\&canny edge extraction
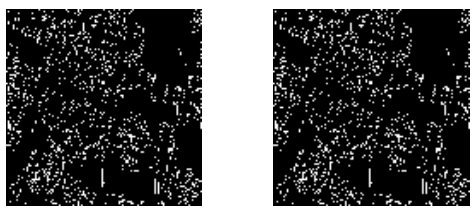

(c)

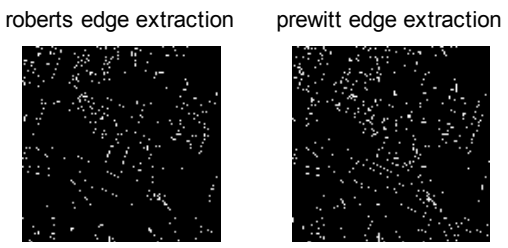

canny edge extraction gasuss\&canny edge extraction

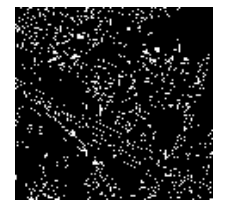

(f)

Fig. 4. Edge-extraction results obtained with different methods: (a), (d) original images; (b), (d) images edgeextracted using the modified Pal and King technique; (c), (e) images edge-extracted using the other edge operators (see also the text).

After the reference and target images are edge-extracted with the improved fuzzy-edge detection algorithm, they are Fourier transformed by the lens, and the JPS is caught by the CCD. Then the JPS is processed using the high-boost filtering, so that the low-frequency noise is eliminated and the main details of the JPS are kept and enhanced. After the processed JPS is Fourier transformed again by the lens, the correlation is recorded (see Fig. 5a, b). To visualize the improvements introduced by our algorithms, for comparison we display in Fig. $5 \mathrm{c}, \mathrm{d}$ the correlation output for the JTC with no processing. The correlation peaks shrink from large blurred spots seen in Fig. 5c to small bright points seen in Fig. 5a, whenever the JTC is processed using the method put forward in the present work. Moreover, when the JTC is not processed, the power of the correlation is concentrated mainly in the zero diffraction order. This makes the autocorrelation peak much stronger if compared with the cross-correlation peaks. On the other hand, the power of the auto-correlation is weakened efficiently when the JPS is modulated by the highboost filter. Then the power concentrated in the auto-correlation peak becomes less and, moreover, the cross-correlation peaks are narrowed. Therefore, one can find the centroids of the crosscorrelation peaks more easily and accurately.

When the correlation is obtained, one has to find the actual positions of the two crosscorrelations according to Eq. (4), in order to measure the image shifts. This is accomplished via searching for the maximal intensity points in rectangular regions $9 \times 9$ pixel $^{2}$ around the points 
$(0, \pm 2 a)$. Making these two points as centres, we then find a centroid $5 \times 5$ pixel $^{2}$ around these two peaks in the output plane. Finally, we subtract the coordinates of the centroid from $(0, \pm 2 a)$ and calculate the mean of the two differences, which is the image shift searched for. The centroids of the cross-correlation peaks can be found easily and quickly, because the peaks after processing represent sharp points. As a consequence, our method improves essentially both the measurement accuracy and its speed.

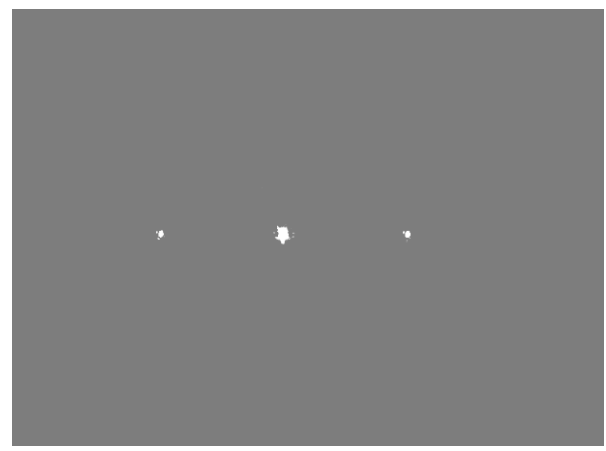

(a)

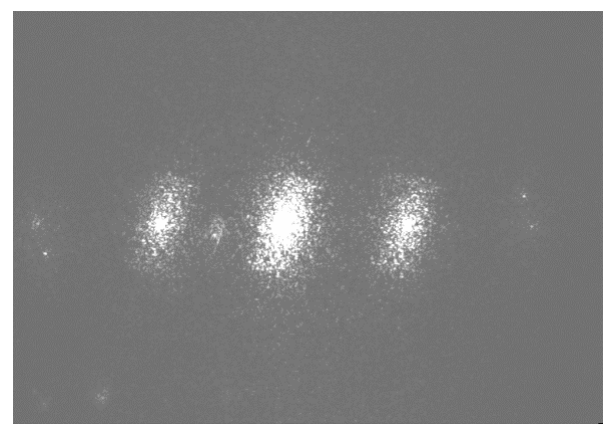

(c)

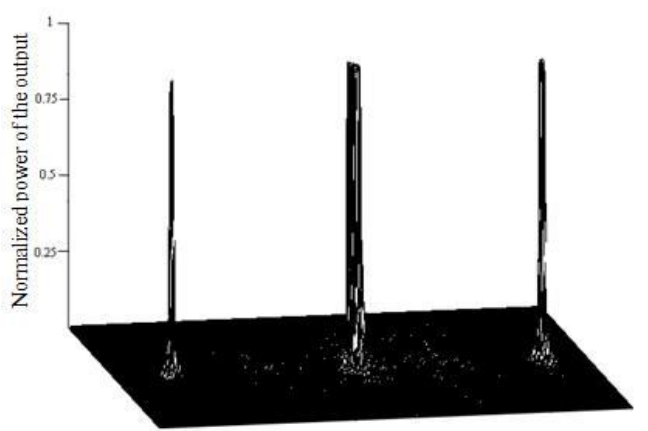

(b)

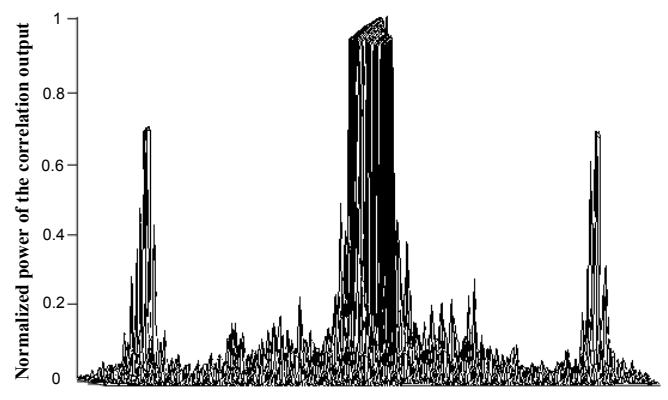

(d)

Fig. 5. Correlation outputs found for the processed (a) and unprocessed (c) JTCs, and normalized power distributions found for the processed (b) and unprocessed (d) JTCs.

Fifty sub-images with the sizes $256 \times 256$ pixel $^{2}$ have been extracted from remote sensing images, and different sub-pixel shifts in the range 0-50 pixels added to these sub-images. After down-sampling the images, the shifts in the range $0-25$ pixels have been measured using the processed JTC. The mean measurement error and the standard deviation are equal to 0.013 and 0.087 pixel, respectively. Then the errors found in the measurement sample have been tested with a standard statistical technique. The results show that the measurement error is governed by the normal distribution. The corresponding mean is equal to zero and the mean-square deviation is less or equal to 0.095 pixel under the confidence level 0.05 .

Analysis of our experiments has demonstrated that there are a number of factors that affect the measurement accuracy. These are non-uniformity of the transverse laser-light distribution, structural defects of the SLM, defocusing of the CCD, etc. At present, the measurement errors of the image shifts usually achieve $10^{-1}$ pixel in the order of magnitude [3, 20-22]. However, the measurement accuracy in our experiments can, in principle, become still higher, $\sim 10^{-2}$ pixel. In other words, the measurement accuracy can be improved largely when the edge of the input image is extracted with the modified fuzzy edge-detection algorithm by Pal and King, and the JPS is enhanced by the high-boost filtering. 


\section{Conclusion}

To improve the measurement accuracy for the shifts of images taken with high-resolution space cameras, information on the main details of the input image should be extracted and irrelevant information weakened, using the modified fuzzy edge-detection algorithm. At the same time, the low-frequency noise of the JPS can be eliminated and the main details enhanced with the highboost filtering. After the JTC is processed, bright, sharp and high-power correlation peaks are obtained, from which the sub-pixel image shifts can be measured accurately and quickly. Our experimental results show that the mean measurement error is less than $\sim 0.1$ pixel. This can meet important requirements to compensating the image shifts in the space cameras.

\section{Acknowledgments}

This project is supported by the Key Laboratory of the Grain Information Processing and Control of the Ministry of Education of China (No KFJJ-2017-106), the Science and Technology Support Project of the State Grain Administration (No 201413001), the National Natural Science Foundation of China (No 61601170), the Natural Science Foundation of the Henan Province (No 162300410062), and the Key Project of Science and Technology of the Henan province (No 162102210198).

\section{References}

1. Fan C, 2017. Research on the influence of the velocity-height ratio of the remote sensing camera on the image quality. J. Opt. Technol. 84: 45-51.

2. Fan $\mathrm{C}, \mathrm{Li} \mathrm{YC}$ and $\mathrm{Yi} \mathrm{H} \mathrm{W}, 2007$. Influence Analysis of Buffeting on Image quality of TDICCD Camera. Acta Photon. Sinica. 36: 1714-1717.

3. Liu Haiqiu, Xu Shuyan, Wang Dong, Yan Dejie, Li Weixiong, 2014. Space camera image motion measurement based on images from time delayed integration sensors overlapped area. Acta Opt. Sinica. 34: 116-122.

4. Fan $\mathrm{C}, \mathrm{Li} \mathrm{Y} \mathrm{C}$ and $\mathrm{Yi} \mathrm{H} \mathrm{W}, 2007$. Influence analysis of drift angle on image quality of TDICCD camera. Opto-Electron. Eng. 34: 70-73.

5. Loyev V and Yitzhaky Y, 2006. Initialization of iterative parametric algorithms for blind deconvolution of motion- blurred images. Appl. Opt. 45: 2444-2452.

6. Likhterov B and Kopeika N S, 2004. Motion-blurred image restoration using modified inverse all-pole filters. J. Electron. Imag. 13: 257-263.

7. Grycewicz T J, Evans B E and Lau C S, 2005. Joint transform optical correlation applied to sub-pixel image registration. Proc. SPIE. 5908: 1-9.

8. Elbouza M., Alfaloua A, Brosseau C, Ben Haj Yahia N, Alam MS, 2015. Assessing the performance of a motion tracking system based on optical joint transform correlation. Opt. Commun. 349: 65-82.

9. Sidike P, Asari V K and Alam M S, 2014. Illumination-invariant pattern recognition using fringe-adjusted joint transform correlator and monogenic signal. Proc. SPIE. 9024: 90240C.

10. Qi Li, Zhihai Xu, Huajun Feng, Peng Ge, Yueting Chen, Lianghui Li, 2007. Influence of noise on detection accuracy of joint transform optical correlator. Proc. SPIE. 7850: 78502M.

11. Fan Chao, Li Yingcai, Fu Hongliang, Yang Tiejun, 2011. Influence of defocusing on measurement accuracy of image motion of space camera. Acta Opt. Sinica. 31: 252-258.

12. Tao Liu, PengGe, Qi Li, Huajun Feng, Zhihai Xu, 2013. Displacement measurement for color images by joint transform correlator. Optik. 124: 162-165. 
13. Wang $Y$ and Zhu M, 2010. Preprocessing input plane image of joint transform correlator based on swarm intelligence method. Opt. Precis. Eng. 18: 958-964.

14. Xu B Q, Guo Y F and ,. 2014. Improvement of joint transform correlator for measurement of space camera image motion. Opt. Precis. Eng. 22: 1418-1423.

15. Sidike P, Asari V K and Alam M S, 2015. A robust fringe-adjusted joint transform correlator for efficient object detection. Proc. SPIE. 9477: 947707.

16. Dou Shuaifeng, Lei Ming, Shen Xueju, Chao Lin 2016. Joint Fresnel transform correlator based on phase encoding. Laser Optoelectron. Progr. 53: 120701.

17. Pal S K and King RA, 1983. On edge detection of X-ray images using fuzzy sets. IEEE Trans. Pattern Analysis Machine Intelligence. PAMI-5: 69-77.

18. Jubai A, Jing B and Yang J, 2006. Combining fuzzy theory and a genetic algorithm for satellite image edge detection. Int. J. Remote Sensing. 27: 3013-3024.

19. Yong $\mathrm{Y}$ and Shuying H, 2008. Modified Pal and King algorithm for fuzzy edge detection. Chin. J. Sci. Instrum. 29: 1918-1922.

20. Yi Hongwei, Li Yingcai, He Tianbin, Li Xuyang, Zhao Hui 2012. Sub-pixel image motion measurement of space camera based on JTC-CDMA. Infrared Las. Eng. 41: 1635-1640.

21. Sun $\mathrm{H}$ and Zhang S M, 2012. Computation model and error budget for image motion of aerial imaging system. Opt. Precision Eng. 20: 2492-2499.

22. Dai Chaoyue, Ge Peng Li, Qi Feng Huajun, Xu Zhihai, 2011. Image displacement measurement using double phase-encoding joint transform correlator. Acta Opt. Sinica. 31: 127-133.

Fan Chao. 2018. Measurements of image shifts using an edge-extracted joint transform correlator. Ukr.J.Phys.Opt. 19: 121-131.

Анотація. Для високоточних вимірювань субпіксельних зрушень зображень космічних камер з високою роздільною здатністю запропоновано вдосконалений алгоритм кореляції з сумісним перетворенням (КСП), який поєднує виявлення невизначеності країв зображень $i$ високошвидкісну фільтрачію. У роботі пояснено принщип вимірювання зрушень зображень на основі КСП. Враховуючи, що більшість важливої інформаиії міститься та описується краями зображення, для вилучення крайової інформачії вхідного зображення використано модифікований алгоритм розпізнавання нечіткого краю Пала і Кінта. Об'єднаний спектр потужності піддано високошвидкісній фільтрайї для посилення компонентів, щэо містять деталі зображення, а також усунення низькочастотних шумів. Нарешті, побудовано відповідну експериментальну платформу та вивчено ефективність вимірювань зрушень зображень на основі покращеного КСП. Результати засвідчують, що помилки вимірювань розподілені нормально з нульовим середнім значення та середнім квадратичним відхиленням, меншим за 0,1 пікселя, якщо зрушення поміж двома корельованими зображеннями змінюється від 0 до 25 пікселів. Як наслідок, запропонований метод КСП може з високою точністю вимірювати субпіксельні зрушення зображень. 